\title{
CUSTOMER RELATION MANAGEMENT APPROACH: ASSESSMENT OF BUSINESS STRATEGY REGARDING TO SOFTWARE ARCHITECTURE FOR THE SERVICE INDUSTRY
}

\author{
DOI: 10.17261/Pressacademia.2020.1284 \\ JMML- V.7-ISS.3-2020(2)-p.112-123
}

\section{Aysenur Erdil}

Istanbul Medeniyet University, Istanbul, Turkey. aysenurerdil@gmail.com, ORCID:0000-0002-6413-7482

Date Received: June 12, 2020

Date Accepted: September 11, 2020

To cite this document

Erdil, A., (2020). Customer relation management approach: assessment of business strategy regarding to software architecture for the service industry. Journal of Management, Marketing and Logistics (JMML), V.7(3), p.112-123.

Permanent link to this document: http://doi.org/10.17261/Pressacademia.2020.1284

Copyright: Published by PressAcademia and limited licensed re-use rights only.

\section{ABSTRACT}

Purpose- The purpose of this research is to define new cross-departmental processes for business which assign them to apply the four steps in Customer Relationship Management (CRM) cycle: plan, relation, process, leverage and then plan a new structure. From this point, this research includes the topic which has been preceded for a CRM solution. This study also involves a research management steps due to business application in service industry. In addition, the research comprises requirement analysis which depends on the business objectives-requirements for the service sector.

Methodology- During the research, the business and software development processes of the study were applied. After the business research development, architecture of requirements of software and UML (Unified Modeling Language) Structure of the service industry, big data were prepared and warehoused-stored for the next research and development for this area-subject.

Findings- Finding methods and components of use cases and foundation of UML structures are fundamentals of the study during the research. This study classifies one of the hundreds of use cases as an instance and UML diagrams that define the work-flow of a specific point of business for the service industry.

Conclusion- Customers in Retail Industry were developed more price sensitive, less brand loyal and more sophisticated. To provide guest loyalty, retailers in business tried to improve CRM strategies which purposes to seek, collect, store and separate guest information throughout the entire organization for creating personalized, unique visitor's experiences. Software solutions and new technologies could facilitate the new ways of working required by a CRM invention would not, in itself, deliver increased customer satisfaction.

Keywords: Business, customer relationship management (CRM), industry, strategy, unified modeling language (UML).

JEL Codes: L21, L80, L21

\section{INTRODUCTION}

Customer Relations Management (CRM) is a technique by which corporations maximize productivity through increasing customer loyalty. It is about automating and improving the customer-centric Sales, Marketing and Service business processes. It also chooses to focus on added customer loyalty that has a direct impact on the bottom line of the organization. CRM philosophy is an enterprise that gives a vision of how an enterprise wishes to deal with its clients. A CRM strategy that shapes sales, marketing, and customer service and analysis activities is required to achieve this vision. For most companies, the aim of a CRM approach is to optimize productive consumer interactions by growing the interest of both the vendor and the client. Frequently CRM applications only present one or two CRM process components. Consequently, a significant proportion of CRM programs focused on the introduction of a single product or series of software do not enhance consumer service, boost client engagement or provide the manufacturer with a return on investment in the form of improved revenue or benefit (Brown, 1999; Buttle, 2004; Lindstrand, 2006; Wang and Burton, 2008). 
Software Requirements due to CRM for the service industry is declared these definitions: The analysis of the software requirements consists of three main components: the presentation of the application, the general overview of the framework and the basic requirements. The introduction provides us with details on the text itself. Such material contains a description of the intent of the manual, a summary of the nature of the program, a set of terms and acronyms included in the process and a number of all materials related to in the part. The presentation also provides a description of the framework for which specifications are defined in the software requirements documentation. The purpose declaration of the framework must be compatible with the current higher-level specifications report. It implies that if the process specifications definition, philosophy of action or dream document occurs for the program, the compilation of high-level specifications can be an appropriate approach for establishing this correlation. The higher-level specifications should also be cross-referred to in the areas of this application specifications report that apply to them. The overall explanation offers a holistic, descriptive view of the method. Company, consumer and device specifications, if they occur, are defined elsewhere. The program specification modeling structure includes a product-service industry overview portion such that this framework can be represented in detail. To this end, the overall description includes five dimensions: product-service perspective, product-service functions, user characteristics, assumptions and dependencies and requirements. The edition of the Application Specifications manual used in the change management system technology specifications assessment committee recorded specifications for the implementation of business systems. The purpose is for professional workers to be willing to continue with planning, development and testing. Modeling, product-service features, user classes and characteristics, and operating environment are the overarching vision clearly explained in the supporting documents (Ang and Buttle, 2006; Tohidi and Jabbaria, 2012; Steel et al., 2013; Vaish et al., 2016).

The Market Requirement group by means of CRM has completed out all the details that other clients have in order to differentiate situations from company criteria, market guidelines, technical specifications, efficiency goals, alternative proposals and other products. The final deliverables from these analyzes are the product specifications, which are an understanding between developers and users on the features, efficiency and implementation constraints. The requirements of the software are organized and written in a way that is easy to understand. The specifications of the software strategies aimed out the functions and capabilities that perhaps the structure have to provide and the restrictions that must be met (Ang and Buttle, 2006; Tohidi and Jabbaria, 2012; Steel et al., 2013).

The Service Industry owing to CRM is distinguished by the idea that awareness of the consumer base, preferences and behavioral patterns are important for growth. Employees still work with and remain with clients through the operation and must maintain loyalty at a high degree such that they might collect input with potential sales. Hotel chains and restaurants are interested in maintaining their essential customers and improve service quality. According to this subject, there are too many platforms to meet this requirement. The starting purpose of the process and the purpose of the study are to explore such approaches. Although certain specifications have been identified for alternatives, certain of them are described in the management requirements report. Application could be structured to achieve consumer satisfaction, which means all the potential and anticipated qualities of the client, for example, what he/she might like first and then when and how he/she should fulfill his/her specific needs. In doing so, it would allow it easier to reduce the time consumed by the consumer when carrying out its activities by offering a convenient way to access through the web and a service structure that often fits the required solution. As a consequence, the incentive and marketing functions integrated business strategy due to CRM with software-UML modeling of the service is highlighted the consumer interest in the scope of the research. So internet content can act both as a promotional tool and as a distribution platform. A collection of main tactics that push the field of responsibility has been drawn up.

\section{LITERATURE REVIEW}

\subsection{Customer Relationship Management- Oriented Market Strategy}

The certain Marketing automation approach- Customer Relations Management (CRM) should develop a vision and plan that outlines the goals and objectives of the company. So you need to change the procedures and internal systems so that you can successfully enforce the approach. Such systems need to be underpinned by a CRM system that integrates contact networks with CRM software and consumer data repositories. In fact, the expenditure in CRM will provide resources from all three application areas - integrated, organizational and strategic CRM - in order to serve the four stages of the CRM lifecycle (Gray and Byun; 2001; Greenberg, 2004; Bohling et al., 2006; Kumar, 2010).

A CRM-based market strategy helps companies to recognize such high value clients and then treat them in a way that keeps them loyal. At the consumer's point of view, the importance of the partnership is a feature not only of the traditional "four Ps" 
price, product, position and promotion but also of the consistency of consumer experiences over time with a supplier. The number of effective customer networks, including the telephone, the World Wide Web, email, interactive digital television and traditional high street and direct mail, is becoming more and more complex as the customer demands are being met and the customer relationship is managed. Only if businesses embrace a strategic strategy that puts the client at the forefront of company strategies and procedures can they thrive. Furthermore, corporations need to visualize CRM as a cyclical process that treats customer relationships not as one-off events, but as interactions that develop and enhance over time in many years-term relationships. The turn of focus is the product of certain far-reaching systemic reforms taking place in many economies and industries. Second, transactions have been increasingly open because consumers have found it easy to find details from potential sources through emerging technology such as the World Wide Web. Because consumers are now in a position to evaluate suppliers and their products more effectively and reliably, the "fee" for consumers to swap between suppliers has fallen and the consumer turnover has risen significantly. Therefore, the demands of consumers increase that Improved openness ensures that people easily learn all the positive ideas of certain vendors, and the areas in which technologies can be utilized to promote contact between businesses and their customers. Customers want retailers to be willing to produce quicker and in forms that are easier for the consumer rather than the manufacturer. As a result, clients are searching for services that, depending on the business, are more or less individualized and "aware" of previous experiences between the customer and service provider (Firth, 2001; Winer, 2001; Kostojohn, 2011; Hillebrand et al., 2011).

Business performance and Requirements of Customers: Retail-service sector is distinguished by the assumption that consumer base awareness, preferences and behavioral features are important to growth. They are always working for customers and being with them during service, and must maintain high level of satisfaction so that they can collect feedback for future sales. Consumer spending was on the decline, and consumers became conscious of the value. Hotels, cafes, and restaurants are able to retain their core clients by increasing the standard of service. There are too many platforms that support that requirement. The research's starting point begins with the research into these solutions. Although certain conditions were looked for alternatives, certain of them are described in the Business specifications of the research.

\subsection{Process of Business and Software Development}

Sustainable development comes with developer team appearances and there is no natural scientific method. The approach takes guidelines in which the efficient execution of the project comprises of a sequence of phases and processes with various methodologies. Common approach for application applications such as RUP (Rational Unified Process), CMM (Maturity Method of Capability). Generally, at the end of the development process, the Agile Methodology follows a succession of steps with formal signs. The specifications of the user are collected, requirements are made, design is developed and the project is completed.

Processes of Business and Software are managed in accordance with these segments, but procedures are carried out through various techniques, and the evaluation, development, design and deployment stages are classified into a dynamic couple of short adaptive development process which is an original strategy which is built by project teams for Cloud platform. The basic methodological characteristics are declared like this respectively; The application developers are significantly smaller than usual; the development staff is incorporated and deeply committed to the project (i.e. consultants, project managers, testing staff), the stages of development are shorter and very dynamic, every version release contains the actual customer needs functionality, releases are not whole prototypes but are work systems that are usable, tasks and activities are not carried out sequentially at the same time, the entire method is based on gradual improvements, typically culminating in a commodity of consistency and the management manager knows that the work requires regular adjustments (Devlin and Murphy, 1988; Stevens and Pooley, 2000; Wilcoz and Gurău, 2003; Aier and Fischer, 2011). In this scope of the study, the first step involves the simulation of business processes and software systems enabling it by implementing a UML-based modeling description and being appropriately generalized for the portrayal of business processes. The second phase concerns the assessment of the degree of alignment through the assessment of a set of metrics coding the concept of alignment. Ultimately, the last step analyzes the findings of the test to recommend developmental behaviors when misalignment is observed. According to this issue, Business Process and Software Development (BPSD) is a method-focused management field that encompasses software modeling, product systems, enterprise process management and research service tools for human resources, organisations, applications, documents, and other sources of information. BPSD is a strategic method that utilizes methodologies and techniques for business operations and improvement for support, design, analysis and implementation. BPSD supports marketing processes for process design, process modeling, process execution, quality control and process optimization (Koster, 2009; Schmidt and Nurcan, 2010; Aversano et al., 2016). 


\section{MANAGEMENT OF BUSINESS AND SOFTWARE DEVELOPMENT}

The team members are a business goals analysis team, an analysis team for software demand, an architecture working group and a software development team. When data and report categories and tools were created, information such as documentation, data flow charts and entity - relationship diagram charts were evaluated which are used to transmit information. If the system architecture specifications are not appropriate, all methodologies will begin from the outset. If they are appropriate for proposed system, framework will continue with the software components being determined. The documentation and records are gathered by the program configuration review department, and functional and non-functional specifications were created. Modeling and software development operations begin after all those processes (Devlin and Murphy, 1988; Wilcoz and Gurău, 2003; Aier and Fischer, 2011).

The issue is described something which has occurred that could threaten the outcomes of the program. With issue management, we can deal with barely conscious major problems, which indicate some problems that are not well recognized but that occur and could lead to problems in the next steps (March and Smith, 1995; Aier and Fischer, 2011; Blake and Mangiameli, 2013). The research on the issue of coordination varies from the abstraction point and deals with issues that it considers. A literature review has enabled the paper on alignment to be divided into two major categories on strategy formulation and practical alignment. Strategic coordination with IT occurs when the objectives, procedures and practices of a corporate enterprise are matched with the information structures that serve it. The functional degree involves the coordination of business processes and operating systems and aims at improving the effectiveness of technical help during the development of business practices (Mckeen and Smith, 2003; Ullah and Lai, 2013; Aversano, 2016).

\section{Figure 1: Project Flow Chart-Business Management of the Software Development}

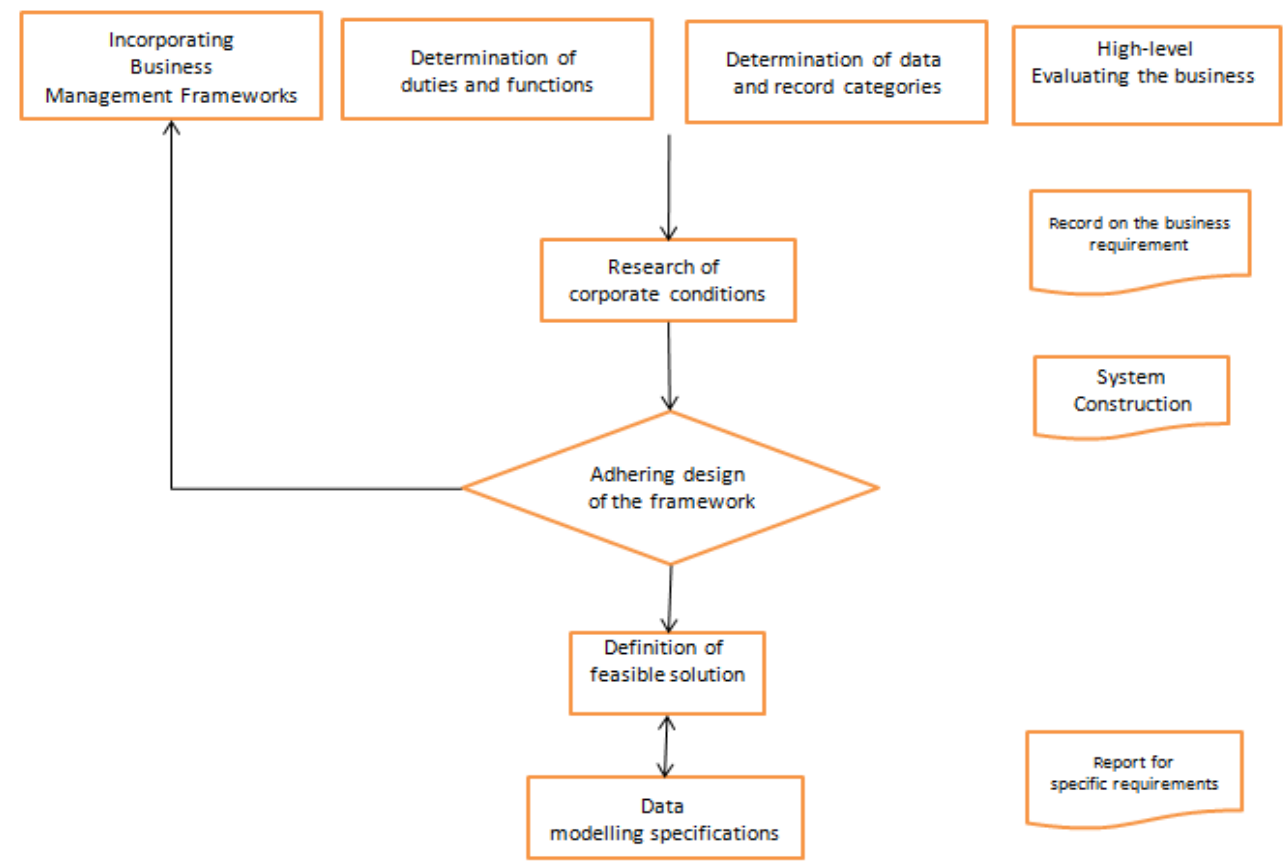

For example, when the requirements gather together, some of them could indicate the same features but could not be implemented until the overall view comes so that some wrong logical aspects of the requirement analysis could be avoided. In comparison, there is another form of problem, mutual problems that remain classified (March and Smith, 1995; Aier and Fischer, 2011; Blake and Mangiameli, 2013). A process is formulated for the development team when individuals accept one of these topics in Figure 1. 


\subsection{Business Development and Change Management}

Change management is the aspect that distinguishes performance and failure, this method is tailored to the project CRM. Although the industry of change management continues to expand through books, conferences and advisors, executives remain as frustrated as ever when challenged as part of the CRM program to incorporate effective change management. CRM attempts to customer-center the entire company and these new position directives structural changes throughout company. Successful change management consists of five key initiatives: internal marketing of transition, developing a appropriate change management framework, CRM-relevant planning, reconfiguring the corporate layout and success evaluation requirements, and remodeling current reward structures. Control of consumer partnerships has been described in different forms as infrastructure, a revolutionary method or a technique. While it has aspects of all of these, it is, above all, a customer-centric philosophy as old as the business strategy itself. In the ideal situation of CRM, this philosophy is transformed into a business model through the use of information systems and acceptable business systems. The outcome (again in the perfect world) is a smooth, reliable and excellent consumer service across a variety of touch points, which transforms into optimizing the company's partnership resources (Gray and Byun, 2001; Greenberg, 2004).

The basic driving concepts for the implementation of transition often refer to CRM. Which include articulating a clear argument for reform, proactive commitment to people's concerns, beginning the project at the very top, engaging any tier in the company in the change effort, establishing high management control, designing an effective engagement plan, giving due consideration to the corporate climate and creating an effective program in incentives and punishments to communicate with channels In fact, if change strategy is to work, an enterprise 's existing consumers (the employees) will first be persuaded on the desire for improvement. Excluding effective staff buy-in, no CRM approach would definitely get out of the surface (Gray and Byun, 2001; Pan and Lee, 2003; Greenberg, 2004).

Figure 2: Change Management in Customer Strategy of the Research

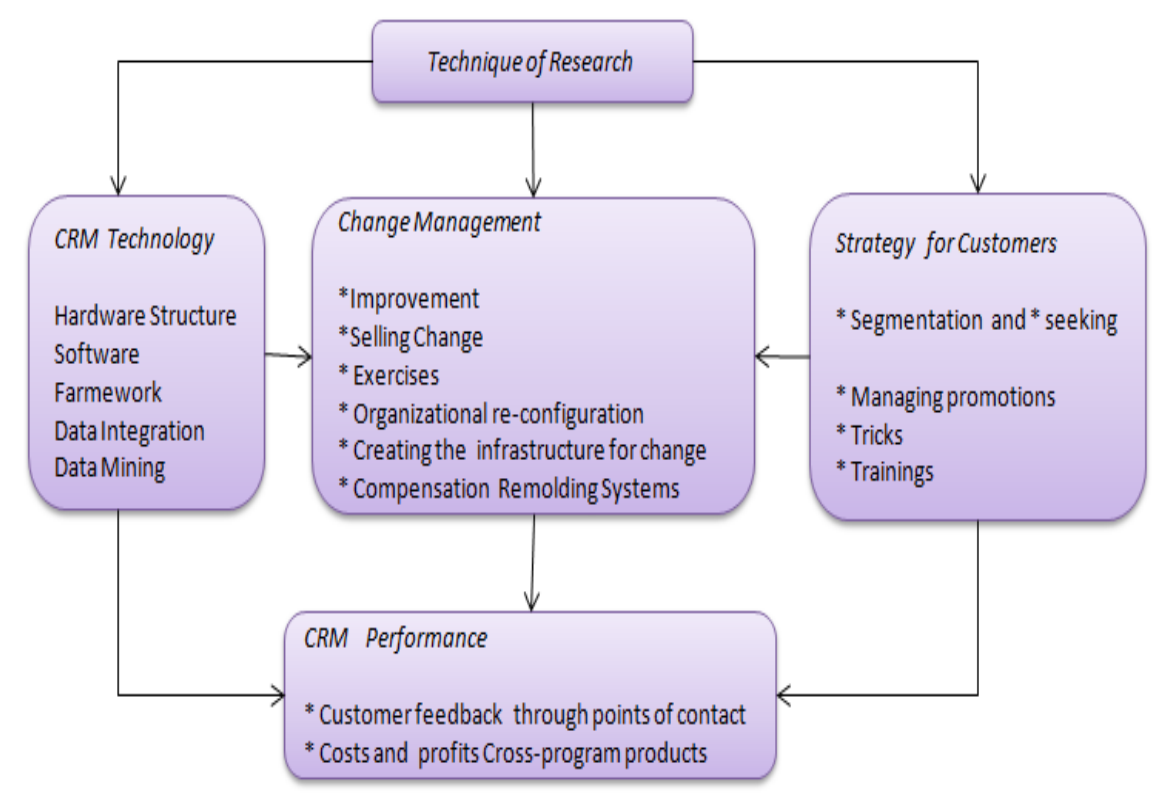

Change management is driven by the CRM approach and influenced by the technical system and the consumer behavior that emerge from the CRM strategy. Change management includes five broad initiatives: internally selling change, setting up a change infrastructure and training, reorganizing the structure of the organization and performance assessment methods of the corporation, and remodeling emerging compensation policies. The frequently utilized change management strategy in the construction process has the specific procedure as below (Winer, 2001; Greenberg, 2004).

1. Turn on the changes.

2. Carry out an effects study on the goods in the job. 
3. Evaluate the effort required to process the requests for change.

4. Reestimate timeline for production.

5. Execute a total combined assessment of the cost impacts.

6. Control the effect with management.

7. Obtain sign-off from the client.

8. Contract services for redesign.

According to this issue, a structure of the organization integrated with performance assessment methods of the business and remodeling emerging compensation strategies can be designed as shown in Figure 2 for CRM System of the Retail Industry.

\subsection{Modeling-Unified Modeling Language (UML)}

Models are already constructed so that we can better understand the process researchers are modeling, because we cannot fully comprehend such a system. The simple implementation of reality that illustrates the system in its entirety from a biased viewpoint. Modeling is beneficial because it enables us to conceptualize, specify, construct and document the structure and behavior of the system architecture for the development team. Use a common modeling language such as the Unified Modeling Language (UML), members of the production team may easily express their conclusions to each other. UML is a structured entity simulation graphic programming tool. It is a terms of strategy based model with a graphical notation. This is used to build a conceptual system model, called a UML model. The UML can be used for computational systems architecture, statistical process control and organizational structure representation (Conallen, 2000; Wilcoz and Gurău, 2003; Glezer et al., 2005). UML is a common language in which features from software processes and business modeling and other non-software systems may be specified, visualized, constructed and documented. The UML reflects a selection of the best technical practices in the design of broad and complex systems which have been successful. UML is an essential aspect of the creation and growth of objectorientated applications and software. The UML usually uses graphic notes to show software projects architecture. The UML assists the management team in collaborating, testing possible projects and validating the software's architectural Development (Conallen, 2000; Stevens and Pooley, 2000; Wilcoz and Gurău, 2003).

Goals of UML: The main objectives in UML design are listed like this respectively; The first one is enable users to develop, share functional templates, in a ready-to-use, interactive digital modeling language. The second one is specific mechanisms to extend the core concepts to include extendibility and specialization. The third one is to be independent of specific languages and development processes of programming. The fourth one is to formally establish a basis for understanding the language of modeling. The fifth one is faster growth of the market for object-oriented tools. The sixth one is compatibility with principles for higher level development, such as partnerships, system models and components. And the last one is to complete recommended method (Stevens and Pooley, 2000; Glezer et al., 2003).

Using UML Modeling provides improving strategies for automating software development and increasing efficiency and rising costs and time for business usage. This includes the technology of the components, visual programming, designs and frameworks. Companies are also looking for strategies to manage systems complexity as they grow in size and scale. They identify, in particular, the need to overcome recurring architectural problems, including physical distribution, competition, replication, safety, load balancing and defect tolerance. This type of modelling is used for collecting of objects interacting to accomplish a given ask or series of tasks over time. In order to describe the overall behavior of a system, it is useful to look at the interactions among its components, and its interactions with the environment. Sequence steps present interactions in two dimensions. At the top level, the involved objects are shown. From top to bottom, the order of the method calls between the objects is shown according to a timeline. The modeling structure tells a story about a system. In fact, it has compounded such technical issues with the introduction of the World Wide Web, thus simplifying other items (Stevens and Pooley, 2000; Conallen, 2000; Glezer et al., 2003)

\section{BUSINESS REQUIREMENTS}

Business requirements evaluate the business goals that the client, corporation or project team wishes to achieve. The business objectives set a guidance framework for the remainder of the project. All other functionality and specifications of the company should comply with market requirements. Company specifications therefore do not have adequate information to tell developers what to build. 


\subsection{Overview - Background of Business Requirements}

Business specifications analysis team technical specifications after development of business processes. Typically, business requirements are expressed in the form of integration services, and then they are described as Business Requirements Document (BRD). The purpose is to promote specifications of satisfactory value and detail to allow for the construction of realistic system development. Verification model for the company specifications contains these issues as below (March and Smith, 1995; Klincewicz, 2009; Liu et al, 2009; Blake and Mangiameli, 2013);

-Consumer or consumer needs: business prospects, customer goals and performance requirements, business threats

-Vision of a solution: Statement of vision, Major features

-Range and limitations: original release width, eventual release range, restrictions.

While it was investigated the evidence for the first portion of proposed systems, and then business opportunities were developed according to feasibility study. There are too many implementations that support that requirement. The research development launching point starts with the quest for certain answers.

Four frameworks have been evaluated as to whether they may require this requirement with respect to the above requirements, varying from each other by which different business features they provide and the degree of sophistication and cost factors. For instance, while one can afford low-cost web sales, the other can focus on providing high-cost financials, payment systems. Current Technologies Analysis bases on these properties and sub properties with development of business information system is presented with Table 1 alternately (Devlin and Murphy, 1988; March and Smith, 1995; Klincewicz, 2009; Blake and Mangiameli, 2013).

Table 1: Properties and Sub Properties with Development of Business Information System - Current Technologies Analysis

\begin{tabular}{|l|}
\hline$a$ - Base of data used by implementation. \\
\hline$b$ - Programming language for application development, whether the approach integrates a POS solution that might need customer cards. \\
\hline bl- Online recording when the customer is spending at the point of sale. \\
\hline b2-Whether customer types are defined according to their amount of expenditure in the system, whether they include payment types such as cash, payable or promotion. \\
\hline b3-Types of discount. \\
\hline b4-Estimates analyzing customer expenditures consume description business financial statements. \\
\hline c-For which Cash points load and card check points cap. \\
\hline c1-If specific currency forms and exchange levels are used for the company, \\
\hline d-New Technology compatibility. \\
\hline e-Response to growing consumer requirements by becoming flexible. \\
\hline el- Easy integration with other applications of the system such as accounting. \\
\hline e2- Following Ordering information and keeping data such as addresses kept for delivery of orders; km data, gas consumption, web, sms integration. \\
\hline f-Complexity reporting for Chained Companies, whether it keeps customer account details. \\
\hline
\end{tabular}

Business requirements have evaluated both the series of business activities (use cases) that the development requires and the depth or level at which each use case will be carried out. Business criteria indicated that the usage of cases needed robustness. Comprehensive practical implementation, allowing just minimal implementation, at least initially. Market criteria have had an effect on the design goals for usage cases and their related technical specifications. Using cases that describe how the designed device is to be utilized by its surroundings. This described one usage of the program; that is, it will explain what sequences of acts the program would execute as a reaction to incidents beyond the framework triggered by users. However, it does not detect behavior outside the program; there is just a use case inside the framework. The use case is the comprehensive use of the framework in the specific context that it begins when someone outside the system begins it and finishes when, based on preliminary input, no other input is predicted and no more internal activities are estimated to be carried out Use cases defined the sequence of interrelationships between the system and the environment actor. A different software system or a hardware device that interacts with the system to achieve a useful goal. Another term for the actor is the role of the customer, since the performers are functions that representatives of one or more user groups may play with regard to the program. One actor may communicate with a variety of use cases. This implies that the individual communicates with the experiences of one or more of 
the usage cases identified with that participant. Correspondingly, one use case can communicate with one or more participants, which indicates that many users participate in the use case. Flowcharts have the major benefit of handling very specific operating system definitions in the same sense. For a remarkably wide range of applications, the changeable flowchart model is used in the studies. A flowchart or UML operation diagram is a helpful way to effectively depict the conceptual flow of a specific use case. Cases in usage involve activities carried out within the program as well as explanations in adverse incidents triggered by perpetrators to trigger these acts, which do not contain actions carried out beyond the program. The behavior contained in the usage cases that be of several different types, such as preservation and recovery (Teorey et al., 2006; Monsalve et al., 2011; Yokoyama et al., 2016; Lambolais et al., 2016; Kaimer and Brune, 2018).

\subsection{Assessment Equipment of Software Requirements}

Such models provide data software architecture, UML flow diagrams, object-relation diagrams, state-transition flow charts or public-charts, dialog layouts, class diagrams, system architecture, analytic applications, interaction diagrams, and decision trees that have been notified above. Such frameworks are valuable for creating and researching specifications, as well as for implementing technical solutions. These diagrams help you to model the specific problem or construct computational representations of CRM framework of service business. The system architecture is the most preferred and classic framework in the Objected Oriented Analysis. It illustrates remarkable concepts in a domain (Conallen, 2000; Stevens and Pooley, 2000; Wilcoz and Gurău, 2003). According to this subject, the system architecture can represent a source of encouragement for the structure of some software objects and will be an input to a number of objects analyzed in case studies. The case system may be modified to demonstrate similar notable ideas constrained by the usage of case scenarios in construction for the current iteration. The associated use of case principles and expert perspectives can lead to its development. The model can affect the process agreements, the glossary, and the modeling approach, in particular the software artifacts in the Design Model application layer. Figure 3 displays the consumer account as one of the concept trends for the suggestion database model. There are consumers and consumer records so far. The consumer needs to report to finish the sequence. In the first position, it is represented what the community classification entails and how it is aligned with other classes:

Figure 3: Database Structure-Architecture of Service Industry (ABC Business)

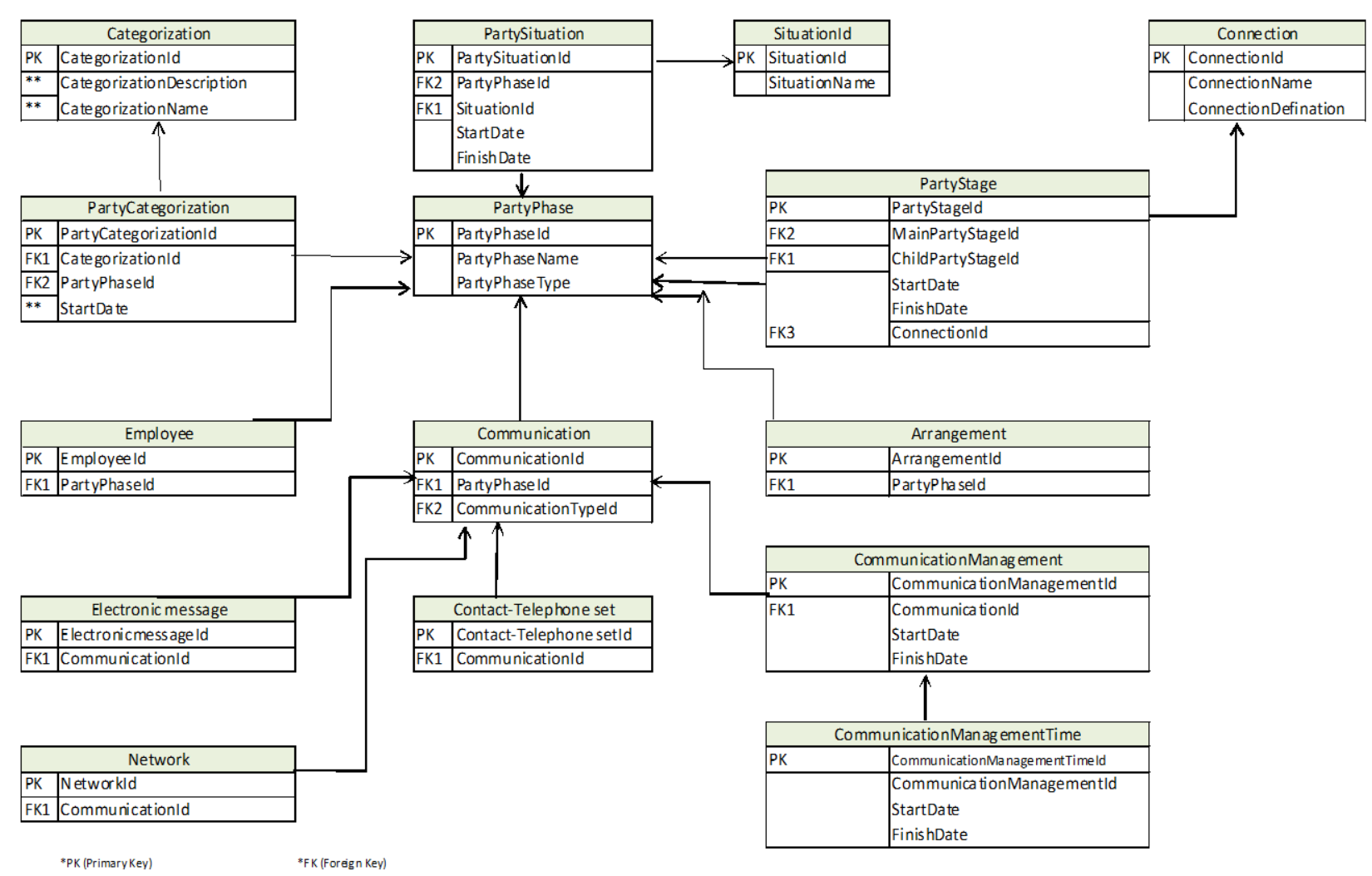


The relationships between CRM framework and other components beyond the broader structure in figure 3 are defined. Such other structures may have frameworks with legacy and non-legacy. The interfaces for CRM and other applications can be illustrated in a diagram. This reveals the interactions and the knowledge between the processes. This is possible to include a concise explanation to how the program is all about client obligations. The consumer is a particular form of party to be registered. Each consumer has a descriptive name: related parties are differentiated by the name of the individual, communication or association. With each category of party, it is important to know the Id and form of party and how many associations the group has with another agency.

\subsection{Perspective on Software Requirements}

Information of the software requirements - Description on the Application Specifications includes three key parts: the framework overview, the general program definition and the particular specifications. The implementation provides us with information concerning the document itself. This material contains a description of the document's intent, a description of the nature of the program, a list of the meanings and acronyms included in the document, and a list of other documents cited in this text. The introduction also provides an description of the framework under which the specification under Program Requirements are relevant. After that developers should hold the generalization of the scope of the organization consistent with any existing documentation of the higher level regulations. This suggests that if the framework specifications definition, procedures principle, or dream framework occurs for the device, the two substances in this portion will be related together. Listing the high-level requirements is an acceptable way to provide this connection. Even we should carry-refer to higher-level specifications for the documentation relating to the categories of this software development (March and Smith, 1995; Stevens and Pooley, 2000. Aier and Fischer, 2011; Blake and Mangiameli, 2013).

The conceptual type of the software architecture under which it was developed originally is recommended by a comparison software design. Therefore, the reference software architecture may be regarded as a kind of traditional software architecture that prescribes the fundamental concepts, the underlying methods and the architectural standards accepted by the framework practitioners as the base approach for the development of a certain type of software structures in that context. Functional requirement specifies the actual behavior that the CRM software demonstrates under certain situations and the actions that the framework will allow individuals to share. The technical specifications originating from program requirements, device requirements, market guidelines and other factors make up the criteria for applications. These define the technical features that developers would integrate into the application to enable customers to execute their functions. For example, the users should be able to organize the list of tasks in forward instead of reverse chronological order is a practical necessity. functionality is a collection of logically linked technical specifications that allows the customer to be able to fulfill the market goal. Favorites or bookmarks for web browsers, spell search, macro logging, phone speed dialing, and automated virus signature alerts are examples of software functionality. A characteristic includes various different use cases, and each use case involves additional functional requirements to be incorporated to allow the user to accomplish the job (Broy, 2010; Monsalve et al., 2011; Casamayor et al., 2012; Panunzio, and Vardanega, 2014; Aversano et al., 2016).

If the system will interconnect with other systems as part of a larger system, the overview section of the introduction is the place to show that. Block diagrams are used for serving this purpose well. If the system stands alone, this is an acceptable place to include the system's context diagram. In some cases, we use both a block diagram and a context diagram. In either case, we should avoid duplicating information that exists elsewhere. So, the information can be summarized and then referenced. The Software Requirements documentation is similar to software: the more places duplicated information, the more effort it must be invested to keep the information consistent and correct and the more opportunity providing to introduce errors (Conallen, 2000; Wilcoz and Gurău, 2003; Glezer et al., 2005; Aier and Fischer, 2011). 
Figure 4: The Purposed Model for CRM Strategy for the Retail-Service Business

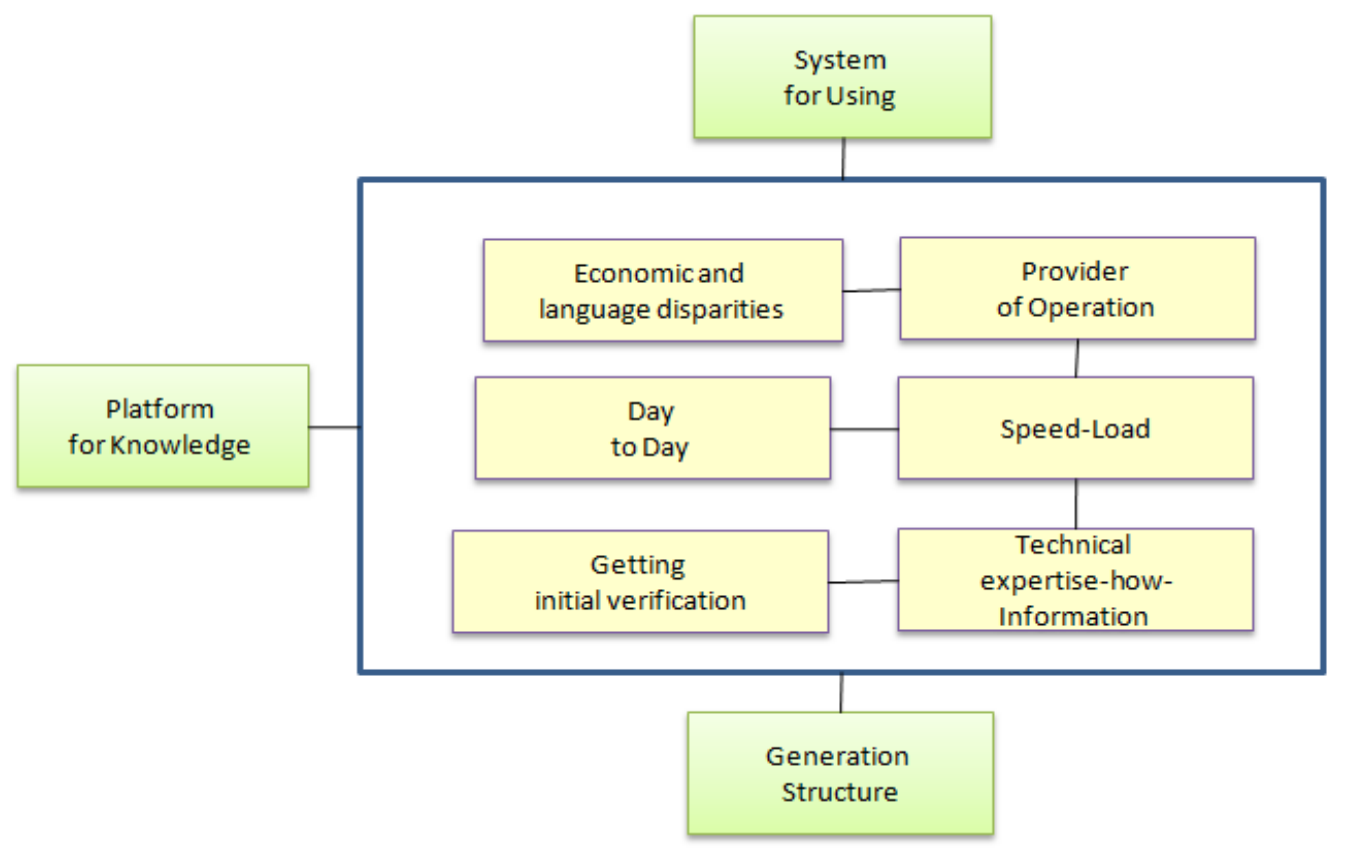

The purposed model for research management steps (improving CRM Strategy) due to business application in service industry for the Retail-service business. The entity and attributes relation diagram of using cases and foundation of UML structures are basis of the study during the study (see figure 4).

This model comprises three frameworks (I) System for Using, (ii) Platform for Knowledge, (iii) Generation Structure are integrated with same entities. These entities are Economic and Language disparities, Provider of Operation, Day to Day, SpeedLoad, Getting Initial verification and technical expertise-information.

\section{CONCLUSION}

The description overall offers a full, conceptual representation of the situation. Business, user, and system requirements are specified elsewhere where they exist. The report on the Program Specifications includes a segment on product viewpoint such that this framework can be presented in detail. To this end, there are five parts of the ultimate description: Product Viewpoint, Product Features, and Consumer Characteristics, Assumptions and Dependencies, and Requirement Allocation. For the Change Management System, the phase of the Software Requirements has been included. These are actors for the system of application.

Use cases have described a sequence of interactions between the system and external actor. An actor is a person, another software system, or a hardware device that interacts with the system to achieve a useful goal. Another name for actor is user role, because actors are roles that the members of one or more user classes can perform with respect to the system. One actor can interact with several use cases. This means that a user will interact with instances of one or several of the use cases associated with that actor. Similarly, one use case can interact with one or several actors, which implies that several users are participating in the performance of the use case. A flowchart or a UML activity diagram is a useful way to visually represent the logic flow in a complex use case. The use cases include the actions performed inside the system as well as descriptions of the external events caused by the actors to initiate the performance of these actions, but they do not include actions performed outside the system.

The purposed model of the study (CRM Model-Information Security) is to investigate the relation between the frameworks and the properties of the framework of information management structure for the design Information System (IS) and the IS with UML. The proposed CRM structure and factors of the suggested model support and enhance the management information processes and help business, users, and customers to survive and compete within today's complex and dynamic environment. 
In today's world, Internet is the leading technology that affects our lives and the way we look at the future. The aim of this research was to get the knowledge and learn the technology behind Internet, and also to learn more about customer relation using Internet. CRM is nowadays a popular application in business life to maintain the activities in the best way by having better relations with the customers and shaping the processes of CRM according to their present and possible needs.

\section{REFERENCES}

Aier, S., and Fischer, C. (2011). Criteria of progress for information systems design theories. Information Systems E-Business Management, 9, 133-172.

Ang, L. and Buttle, F.A. (2006). CRM software applications and business performance, Journal of Database Marketing \& Customer Strategy Management, 14(1), DOI: 10.1057/palgrave.dbm.3250034.

Aversano, L., Grasso, C. and Tortorella, M. (2016). Managing the alignment between business processes and software systems, Information and Software Technology, 72, 171-188, https://doi.org/10.1016/j.infsof.2015.12.009

Blake, R., and Mangiameli, P. (2013). An Information systems design theory for strategic decision systems: the case of a candy manufacturer, Northeast Decision Sciences Institute Annual Meeting Proceedings.

Bohling, T., Bowman, D., LaValle, S., Mittal, V. and Narayandas, G.D. (2006) CRM Implementation: Effectiveness Issues and Insights, Journal of Service Research, 9(2), 184-194. https://doi.org/10.1177/1094670506293573

Brown, S. A. (1999). Customer relationship management: A strategic imperative in the world of e-business. Etobicoke: Wiley.

Broy, M. (2010). Multifunctional software systems: Structured modeling and specification of functional requirements, Science of Computer Programming, 75(12), 1193-1214, https://doi.org/10.1016/j.scico.2010.06.007.

Buttle, F. (2004) Customer Relationship Management: Concept and tools. Burlington, MA: Elsevier.

Conallen, J. (2000). Building Web Applications with UML. Addison Wesley Longman, London

Devlin, B.A. and Murphy, P. T. (1988). An architecture for a business and information system, IBM Systems Journal, 27(1), 60-80.

Firth, D. (2001). The organizing vision for customer relationship management. In AMCIS 2001 Proceedings, 162, 834-840, Boston, MA. Retrieved from http://aisel.aisnet. org/amcis2001/162.

Glezer, C., Nachmany, E. and Shoval, P. (2005). Quality and comprehension of UML interaction diagrams-an experimental comparison, Information and Software Technology, 47, 675-692. https://doi.org/10.1016/j.infsof.2005.01.003

Gray, P. and Byun, J. (2001), Customer Relationship Management, Center for Research on Information Technology and Organizations University of California, March 2001.

Greenberg, P. (2004). CRM at the Speed of Light: Capturing and Keeping Customers in Internet Real Time, McGraw-Hill, Berkeley, CA.

Hillebrand, B., Nijholt, J., and Nijssen, E. (2011). Exploring CRM effectiveness: An institutional theory perspective. Journal of the Academy of Marketing Science, 39, 592-608.

Kaimer, F. and Brune, P. (2018). Return of the JS: Towards a Node.js-Based Software Architecture for Combined CMS/CRM Applications, Procedia Computer Science, 141, 454-459, https://doi.org/10.1016/j.procs.2018.10.143.

Klincewicz, K. (2009). Knowledge management and IT research and analysis firms: Agenda-setters, oracles and judges, In D. Jemielniak and J. Kociatkiewicz (Eds.), Handbook of research on knowledge-intensive organizations, 152-168, Hershey, PA, IGI Global.

Kostojohn, S., Johnson, M. and Paulen, B. (2011), CRM Fundamentals, Apress Publishing, 244 p.

Kumar, V. (2010). Customer relationship management. Hoboken, NJ: Section in Wiley International Encyclopedia of Marketing.

Lambolais, T., Courbis, A.L., Luong, H.V. and Percebois, C. (2016). IDF: A framework for the incremental development and conformance verification of UML active primitive components, Journal of Systems and Software, 113, 275-295, https://doi.org/10.1016/j.jss.2015.11.020.

Lindstrand, A., Johanson, J. and Sharma, D.D. (2006) Managıng Customer Relationships On the Internet, Series Pervez N. Ghauri (Ed.), First Edition, Elsevier Inc. ISBN-13: 978-0-08-044124-5, $319 \mathrm{p}$.

Liu, S., Duffy A. H. B., Whitfield, R. I., and Boyle, I. M. (2009). Integration of decision support systems to improve decision support performance, Knowledge and Information Systems, 22(3), 261-286.

March, S. T., and Smith, G. F. (1995). Design and natural science research on information technology. Decision Support Systems, 15(4), 251-266.

Mckeen, J.D. and Smith, A.H. (2003). Making IT Happen: Critical issues in IT management (Chichester, Hoboken, NJ: Wiley, 2003), 384 Pages 
Pan, S. L. and Lee, J.N. (2003). Using e-CRM for a unified view of the customer. Communications of the ACM, 46, 95-99.

Panunzio, M. and Vardanega, T. (2014). An architectural approach with separation of concerns to address extra-functional requirements in the development of embedded real-time software systems, Journal of Systems Architecture, 60(9), 770-781, https://doi.org/10.1016/j.sysarc.2014.06.001.

Steel, M., Dubelaa, C. and Ewing, M.T. (2013). Developing customised CRM projects: The role of industry norms, organisational context and customer expectations on CRM implementation, Industrial Marketing Management, 42(8), 1328-1344, https://doi.org/10.1016/j.indmarman.2012.08.009,

Stevens, P. and Pooley, R. (2000). Using UML Software Engineering with Object and Components. Updated Edition. Pearson Education Limited, Harlow.

Teorey, T., Lightstone, S. and Nadeau, T. (2006). The Unified Modeling Language (UML), Database Modeling and Design (Fourth Edition), The Morgan Kaufmann Series in Data Management Systems, 33-51, https://doi.org/10.1016/B978-012685352-0/50003-3

Tohidi, H. and Jabbaria, M.M. (2012). CRM as a Marketing Attitude Based on Customer's Information, Procedia Technology, 1, 565-569, https://doi.org/10.1016/j.protcy.2012.02.123.

Ullah, A. and Lai, R. (2013). A Systematic Review of Business and Information Technology Alignment, ACM Transactions on Management Information Systems 4(1), 4-29.

Vaish, A., Vaish, A, Vaishya, R. and Bhawal, S. (2016). Customer relationship management (CRM) towards service orientation in hospitals: A review, Apollo Medicine, 13(4), 224-228, https://doi.org/10.1016/j.apme.2016.11.002.

Wang, P. and Burton Swanson, E. (2008). Customer relationship management as advertised: Exploiting and sustaining technological momentum. Information Technology and People, 21, 323-349.

Wilcoz, P.A. and Gurău, C. (2003). Business modeling with UML: the implementation of CRM systems for online retailing, 3, 181-191, https://doi.org/10.1016/S0969-6989(03)00004-3.

Winer, R. S. (2001). A framework for customer relationship management. California Management Review, 43, 89-105.

Yokoyama, T., Axelsen, H.B. and Glück, R. (2016). Fundamentals of reversible flowchart languages, Theoretical Computer Science, 611, 87-115, https://doi.org/10.1016/j.tcs.2015.07.046. 